\title{
A ESCOLA DIANTE DA CIDADE: REPRESENTAÇÕES UTILIZADAS PELA ESCOLA NORMAL DE BELÉM DO PARÁ (1890-1920) COMO MECANISMO DE LEGITIMAÇÃO
}

\author{
Raimundo William Tavares Junior ${ }^{1}$ \\ Felipe Gustavo Pedrosa Souza ${ }^{2}$ \\ Universidade da Amazônia
}

\section{RESUMO}

Esse artigo propõe analisar a Escola Normal e a cidade de Belém do Pará em tempos de modernização: 1890-1920 em meio ao discurso de progresso no contexto da república recém-instalada. Procura compreender as representações construídas para fazer com que a escola ganhasse visibilidade junto a cidade, legitimando o ideal de progresso, através de símbolos que a afirmavam e a fortaleciam junto com o projeto progressista em um novo contexto social que se desenvolveu, tendo a educação como estratégia fundamental. Foram utilizadas fontes primárias encontradas no arquivo do Instituto Estadual de educação do Pará e no Arquivo Público do Estado do Pará.

Palavras-chave: Escola Normal; Belém do Pará, Belle Époque, Educação. Representações.

\section{SCHOOL BEFORE THE CITY: REPRESENTATIONS USED FOR NORMAL SCHOOL OF BELÉM DO PARÁ (1890-1920) AS MECHANISM LEGITIMATION}

\begin{abstract}
This article aims to analyze the Escola Normal (technical secondary school) and the city of Belém, State of Pará, in the Nothern Anazonia Region, during the pre-modern era between the years 1890-1920, within the in the context of the newly installed republican government and it's discourse of progress. The objective was to understand the constructed representations in an effort to make the school gain visibility in the city. Thus, legitimizing the ideal of progress, through symbols that affirmed and strengthened with the progress design of a new social context that elected the education as its fundamental strategy. The research used the primary sources found in the archive of the Educational State Institute of Pará and at the State Public Archives.

Keywords: Escola School; Belém do Pará, Belle Époque, Education. Representations;
\end{abstract}

\section{Para Começar.}

O presente artigo é fruto do desenvolvimento de um grupo informal de pesquisa sobre a Escola Normal de Belém do Pará entre 1890 e 1920 da Universidade da Amazônia, coordenado pelo prof Dr. Raimundo William Tavares Jr e do qual fazia parte Felipe Gustavo Souza durante o ano de 2013. Tinha como material de trabalho partes da tese de doutorado do professor,, cabendo ao grupo o levantamento de fontes adicionais junto ao Arquivo Público do Estado do Pará e a Biblioteca Arthur Vianna no Centro de Turismo do ParáCENTUR. 
O grupo de estudo visava abordar a escola nos seus mais diferentes modos, buscar novos documentos para criar novas discussões ou futuros estudos sobre a Escola Normal. Em relação ao texto deste artigo, utilizou-se parte do quarto capítulo da tese intitulada "Um Viveiro de mestres: A Escola Normal e a cidade de Belém do Pará em tempos de Modernização: 1890-1920 defendida no Programa de História Social" na Pontifícia Universidade Católica de São Paulo, PUC-SP, após discussão em conjunto.

A Escola Normal no Pará ressurge em 1890 em meio a construção da república, num novo contexto social no qual se buscava o progresso e a distância de um passado monárquico considerado "arcaico". A escola se tornava palco para o desenvolvimento e fortalecimento dos ideais republicanos, a modelagem de corpos e mentes para um ideal civilizatório e disciplinador, crucial para a hegemonia dos novos grupos sociais.

Nesse sentido era de fundamental importância que a instituição se fizesse visível a uma cidade multiétinica e com fortes movimentos imigratórios que passava por um amplo processo de modernização31. Dessa forma, a Escola Normal disseminará de forma simbólica, das mais diversas formas e representações o pensamento republicano que então se constituía.

Em um jogo de representações e manifestações simbólicas, a Escola Normal se utilizará de símbolos e rituais como visibilidade do prédio de linhas neoclássicas, situado no centro da cidade, cerimônias de formatura no Teatro da Paz com participação do governador e iluminação elétrica, diplomas, premiações, com ampla cobertura da imprensa, além de anel e uniforme escolar para mostrar que a educação será a saída para a escuridão deixada pelo regime anterior e legitimar os novos grupos dirigentes.

\section{A Escola entre Símbolos e Ritos}

A Escola Normal fazendo parte de um projeto maior de modernização precisou também de uma grande visibilidade externa para continuar sua função pedagógica e de propaganda política elitista, co-partícipe de uma proposta de civilização e progresso, segundo os termos pensados pelo ocidente. Era necessário mostrar à cidade de Belém que a escola estava cumprindo sua missão de formar professores altamente capazes de ensinar e exercer moralidade e práticas cidadãs. Em nome da jovem república, através da educação, ajudaria a erradicar as mazelas do obscurantismo, do atraso do regime deposto e construir uma sociedade que olhava firme para o futuro linear rumo ao progresso.

Desde a própria monumentalidade do prédio e sua localização, passando pelos quadros de formatura exibidos no salão nobre, as festas de formatura no Teatro, os discursos prêmios, os concursos, até o anel de normalista e uniforme escolar, eram maneiras que ela e eram maneiras que a escola encontrou para se fazer visível, importante e capaz de dialogar com os diversos sujeitos sociais da cidade. Numa sociedade crivada por profundas mudanças urbanas, técnicas e culturais, esses sujeitos responderam a proposta com elogios e críticas, via diferentes canais de comunicação escritos. A professora normalista será, inclusive, objeto de representações literárias e parte das memórias individuais e coletivas que ali se disseminaram.

A esse respeito Rosa Fátima Souza referindo-se aos grupos escolares do Estado de São Paulo, fundados logo após a proclamação da república, afirmou que a cultura escolar assumiu uma manifestação simbólica. Eram cultuados diversos símbolos nacionais como bandeira, escudo e hino, os quais precisavam tornar-se evidentes. Para isso, "exibi-los e solenizá-los" fazia parte da pedagogia civilizadora preconizada e implantada pela escola. 
(SOUZA, 2008). Considerando a circularidade de ideias e mentalidades, a EN42 em Belém foi atravessada por aqueles símbolos e seus sentidos.

Ilustrativo é o ofício de Raymundo Joaquim Martins, diretor da EN, pedindo em 17 de outubro de 1894, uma complementação para o mastro, para que se pudesse hastear a bandeira em dias solenes, sem a qual perderia seu significado e a escola comprometeria seu diálogo com a cidade:

Snr Governador do Estado. Achando-se sem adriça o mastro collocado no frontispício deste estabelecimento, para hastear o pavilhão nacional em dias de gala, peço-vos que vos digneis de dar ás necessárias ordens á Repartição de Obras Publicas no sentido de ser aquella collocada, para que possa o referido mastro prestar o serviço a que é destinado. Saude e Fraternidade." (APEP. Área: educação e cultura: fundo: secretaria do governo. Serie: Oficios: educação: 1891-1900).

Outro símbolo que fazia parte do projeto de formação a ser inculcado no seio da escola e seu alunado, era a representação valorativa de uso do anel de normalista, formato do diploma, solenidade da cerimônia de colação de grau e concessão de prêmios. No Regulamento de 24 de setembro de 1891, o ritual de formatura deveria obedecer a uma sequência de etapas: contaria com a assistência do governador, a congregação marcaria o lugar e a hora da cerimônia e anunciaria por meio de edital, em todos os jornais, com 10 dias ao menos de antecedência, cuja data deveria ser marcada pelo secretário de instrução pública. Era o momento em que a escola procurava tornar-se mais visível à cidade, espelhando uma espécie de prestação de contas de seus resultados.

Diante das principais autoridades públicas, ouvir o pronunciamento de um dos professores do estabelecimento, eleito pelos diplomados, receber os diplomas das mãos do diretor da escola, o qual lia a nota alcançada por cada formando, e escutar o discurso do representante de turma constituíam-se etapas do ritual de colação. (PARÁ, 1894).

Nas festas de colação de grau, a presença do governador era questão de honra e prestígio não só para o próprio governador, que reafirmava o seu compromisso com a educação e o progresso do estado, como para a EN que via reconhecida publicamente a sua importância. A solenidade ultrapassando seus sentidos iniciais tornava-se também ocasião propícia para que a escola fizesse propaganda de sua eficácia e justificasse a necessidade de auferir mais verbas

Os documentos produzidos sobre os festejos de formatura dão conta de mapear os diferentes instrumentos utilizados. Não poderia faltar, por exemplo, preocupações com a música que faria a cobertura da solenidade. Raymundo Joaquim Martins, diretor da EN no período de 1892 a 1895 em um dos registros confirmou essa necessidade. "Peço que vos digneis mandar pôr a disposição d'esta Directoria duas bandas de muzica dos Corpos do Estado, a fim de abrilhantar aquela solemnidade". (APEP. Fundo: secretaria do governo. Serie: ofícios (educação): 1891-1897)

Já em 30 de novembro de 1895, Heitor Barjona de Miranda, em seu pedido ao governador preocupava-se com a iluminação elétrica na noite da colação de grau. (APEP .Fundo: secretaria do governo. Serie: ofícios: educação:1895-1899). Fica-se a imaginar o impacto que aquele recurso ainda pouco difundido, mesmo em Paris, à época, teria nas pessoas que fossem assistir a formatura. Possível ar de esplendor e excepcionalidade marcaria esse momento, perenizando-se na memória dos participantes.

Posteriormente passou-se a reivindicar um espaço de maior visibilidade e imponência para as cerimônias de colação, o salão do Tetro da Paz, ícone da modernidade. "Rogo-vos queautorizeis ao Sr. Dr. Administrador do Theatro da Paz de ficar á disposição 
desta Diretoria, o Salão nobre do mesmo edificio[...] para(... )a sessão solemne da Collação de grao, conforme verbalmente vos solicitei e vos dignastes aquiescer". (APEP. Fundo: secretaria do governo. Serie: ofícios: educação: 1895-1899) Em seguida, ao buscar-se recursos suplementares para a cerimônia que poderia também contemplar a entrega de prêmios, Heitor Barjona de Miranda, escrevia ao governador nesse sentido: [...] habiliteis com o credito necessário para occorrer ás despezas a fazer-se com esta solemnidade, que orçam approximadamente em um conto e duzentos mil reis [...]".(APEP. Fundo: secretaria do governo. Serie: ofícios :educação: 1895-1899)

Podem-se rastrear alguns discursos a respeito da cerimônia de colação de grau que evidenciam a sua relevância. Um deles que pode ser inferido do pronunciamento do Diretor Geral da Instrução Pública, Dr. Virgílio Cardoso de Oliveira, presidindo a cerimônia de Colação de Grau de março de 1900: “(... ) nelas eu vejo sempre um rebate de clarins, tangidos pelos lábios do patriotismo, nos arraiaes da democracia, onde, erguida, a bandeira da Republica anuncia ao monarchismo impenitente a noticia de mais uma victoria benfazeja..." (OLIVEIRA. A Escola, julho de 1900.)

Continuava seu discurso afirmando que a festa de formatura representava certa superação do atraso educacional verificado no período monárquico. Os interesses da escola em ganhar prestígio através da visibilidade de uma cerimônia imponente comungavam-se com os das autoridades, quando se valiam da ocasião para autoproclamarem-se superiores ao regime deposto. Virgílio Oliveira deixou pistas para esse argumento: “[...] estas festas não podem deixar de despertar na consciência popular, pela solemnidade que as reveste, a bôa comprehensão da importância máxima que os poderes publicos ligam á instrucção do povo, accendendo-lhe no espírito o desejo de instruir-se". (Idem). A festa não somente visibilizava os saberes iluminados adquiridos pelos alunos, como se constituía em luz para iluminar ou alertar outras mentes que ali festejavam sobre a necessidade de instrução.

Como a opinião pública, a partir da década de 1870, associava cada vez mais modernidade com melhoria da instrução, o poder público se legitimaria se mostrasse preocupado com a sua difusão. Seria necessário para a manutenção do regime republicano um povo educado e esclarecido. A partir daí atribuía um papel fundamental à figura do professor que não podia ser considerado como um mero funcionário público e que carregaria uma missão. Um discurso muito cômodo que, em troca do prestígio, seria dado ao professor ao tentar mascarar as suas condições econômicas quase sempre precárias. (Idem,Ibidem).

Poderiam ocorrer também festas internas a favor de uma causa como, por exemplo, uma festa organizada em favor dos órfãos e que foi notícia no jornal A República em 1893. A festa procurava ajudar o Orphelinato Paraense por meio de uma quermesse. A propaganda anunciava que o evento seria primorosamente organizado e contaria com "concerto arranjado com o mais apurado gosto". A entrada seria franca, mas era preciso estar "decentemente vestido" (A República. 24 de janeiro de 1893). Descrevia em seguida as músicas que seriam cantadas e tocadas: Hino pelas alunas, árias de óperas de Bellini, poesias, conferência proferida por Paulino de Brito. A festa duraria sábado e domingo e ainda contaria com a presença de bandas musicais.

A escola ao se lançar numa atividade de caridade trazia para si a admiração e a presença das pessoas para ouvir música, conferência e ainda gastar na quermesse em benefício dos órfãos. Suas portas, antes restrita a um público seleto, abriam-se para grupos sociais específicos da cidade. Contudo, longe de popularizar-se nesse momento, porque não haveria cobrança de ingressos, somente um público restrito acabava por adentrá-la.

Curiosamente, a localização do prédio da escola, onde a programação era realizada, o fazia refém de seu próprio preconceito e ação de exclusão social. A Campina, palco desse acontecimento, era um bairro que contava com inúmeras casas, bares e espaços de 
divertimentos populares. A instituição exigia que os convidados vestissem "roupas decentes", expressão codificada para se resguardar de indesejados que provavelmente conseguiam driblar essas determinações.

Em 14 de julho de 1903 foi feita uma sessão solene para a comemoração da reinauguração do prédio da escola que havia passado por uma ampla e profunda reforma e a colocação no salão nobre do retrato do governador. Nessa solenidade compareceram várias autoridades, entre elas o governador Augusto Montenegro, o senador Antonio Lemos, chefe do partido da situação e intendente de Belém. Elias Vianna, professor de pedagogia foi o orador oficial. Apoiando-se em Spencer e Conte, defendia o papel da educação como solução para o progresso humano. (SOUZA, 1972)

Augusto Montenegro por sua vez afirmou a importância da Escola Normal "que passou a ser um laboratório de civilização e de progresso [...]". (Souza, p.50) Nas representações da escola enunciadas pelo orador e pelo governador eram visíveis ideais de que ela seria um espaço vital para elaboração do projeto de modernização então realizado no estado e principalmente em sua capital. (Idem Ibidem).

Outra ocasião bastante importante foi a presença na escola do presidente eleito, Afonso Pena, que estava em visita na capital do estado. Ele compareceu a uma sessão solene da Congregação em 2 de julho de 1906, saudado pelo diretor Heitor Castelo Branco. Isso evidenciava o prestígio e o orgulho das autoridades estaduais em relação à escola a ponto de agendar a visita daquela autoridade no seu espaço onde escola e autoridades ganhava visibilidade perante a opinião pública e tentando talvez responder aos oposicionistas que não tinham da escola um olhar tão otimista. (Ibidem, Ibidem.).

O diploma vai se constituir em outro importante símbolo de distinção. Em 1903, quando foi apresentado o modelo de diploma a ser utilizado pela EN, havia nas dependências da instituição 340 alunas e apenas 48 rapazes. Essa representação feminina, verificada ao longo da história da escola, não foi suficiente para transformar o sentido masculino que predominava na escrita do documento certificador do curso de normalista. Fica claro também que o investimento do diploma era feito pelo Secretario de Estado, representante do poder público que subordinava o diretor da EN claramente à sua autoridade, embora a formatura se desse nessa escola. Não se imagina por que a necessidade de colocação da idade da(o) colanda(o). O diploma seria impresso em pergaminho, selado e registrado em livro especial, o que demonstra a importância que era atribuída pelo governo.

A atribuição de prêmios era um incentivo entre os alunos pelo desempenho escolar. Estimulava a competição e o mérito, ajudando a reafirmar e legitimar a hierarquização social.Em ofício de 15 de maio de 1895 eram estabelecidos critérios para a concessão do Prêmio Justo Chermont. O prêmio seria atribuído ao "ao alumno que, alem de bom comportamento, não tenha durante o tirocinio normal uma só approvação simples e alcance um terço das approvações distinctas". (PARÁ. 1896) O critério orientador exigia disciplina e assimilação de conteúdos, significativamente a exigência de comportamento vem em primeiro lugar provando mais uma vez o caráter disciplinar dos estabelecimentos escolares.

Em 1903 era estabelecido que o Estado concederia um premio ao aluno que mais se distinguisse pelo seu aproveitamento e comportamento durante o seu curso. O prêmio consistia na colocação no salão de honra do retrato do diplomado, abrindo espaço também para que a iniciativa privada pudesse oferecer outros prêmios. Havia também prêmios anuais para as melhores notas obtidas por aluna (o)s de cada um dos três primeiros anos, consistindo de livros relacionados às disciplinas estudadas.

Como se pode perceber a premiação envolvia mais prestígio e status do que compensações financeiras. Era ao mesmo tempo utilizada como mecanismo de competição entre o alunado e incentivador de disciplina, pois envolvia também o critério de bom 
comportamento. Esperava-se que a escola tivesse suficiente visibilidade na cidade para que empresas e particulares estivessem dispostos a ofertar outras premiações e com isso associar seu nome ou seu estabelecimento a uma instituição de prestígio. Uma intensa competição era esperada, pois se previa recurso de aluna(o)s que se sentissem injustiçada(o)s pela escolha feita pela congregação, junto ao Conselho Superior da Instrução Pública.

Outra marca de grande visibilidade da escola seria o uniforme escolar que uniforme vai se revelar peça fundamental de vigilância e controle das normalistas dentro e fora do espaço escolar. A visibilidade das alunas no espaço da cidade multiétnica e multifacetada devia ser bastante recorrente e, a partir daí, era necessário também vigiá-las e, quando estivessem com um comportamento que contrariasse os objetivos educacionais pretendidos pela escola, puni-las. Para o público externo ao estabelecimento era preciso, ao ver o alunado pelas ruas, majoritariamente feminino, confirmar a eficácia do estabelecimento em moldar comportamentos adequados à modernidade e à integridade moral de alunas e alunos. $\mathrm{O}$ diretor, Dr. Eládio Lima, num ofício enviado ao Secretario do Interior e Justiça e Instrução Pública propôs o uso do uniforme:

De há muito, como medida de ordem e fiscalização, e até mesmo como elemento de educação moral, cogita a diretoria desta escola em adotar um uniforme para o uso no estabelecimento, consoente o que se verifica em quase todas as congêneres. A medida, já hoje bem comprehendida pelos alumnos e respectivos pais ouresponsáveis, constitue vivo desejo daqueles a quem diz respeito, principalmetne as alumnas, que compõem a quase totalidade da classe discente, e as quais elle mais especialmente traz vantagens, por torná-las conhecidas quando transitarem pelas ruas da capital, para seus trabalhos escolares [...]. (SOUZA, 1972)

Por que uma medida de ordem e fiscalização seria bem compreendida pelo corpo discente e especialmente pela maioria que eram as alunas? Elas em comportamento inadequado poderiam ser um péssimo cartão de visita à escola. Também é possível que o uniforme viesse atender aos interesses das próprias alunas, pois o transitar de jovens moças e algumas mulheres pelas ruas, algumas vezes desacompanhadas, poderia levar a suspeitas, comprometendo a honra e talvez submeter as educandas a algumas situações constrangedoras. A esse respeito: “[...]Deste modo, tornam-se impossíveis certos enganos maléovolos, sempre prejudiciais aos créditos do Estabelecimento [...]". (Idem) Para o aparelho disciplinar escolar, o controle seria bastante facilitado pelo uso do uniforme, como ainda evidencia o documento: "[...]comportando o distinctivo dos annos de que se compõem os dois cursos facilitará o cumprimento de disposições regulamentares a applicar a um bem avultado numero de alumnas, em proveito da disciplina e do estudo[...]”. (Idem. Ibidem).

O uso do fardamento, provavelmente, não seria consensual entre os poucos alunos, ou não se teria ainda ideia do modelo, porque o diretor falava que a experiência começaria com as mulheres em caráter de obrigatoriedade. Uma proposta para esse novo dispositivo de vigilância e controle foi redigida:

[...] blusa branca, de cambraia de algodão ou linho, com gola e punhos azul marinho, saia simples, pregueada de drill de algodão também azul marinho e chapéu da mesma cor, de abas do tipo 'canotier. [...] botinas pretas de tacão baixo, e substituindo, quando possível o espartilho por uma cinta hygienica". (Ibidem, Ibidem,) 
Nesse momento, confrontavam-se posições de médicos que se mostravam contrários ao espartilho. Como era alvo de debates, deixava-se o seu uso como opcional. Ao reportar-sea cor do uniforme era vago: "[...] A cor azul marinho, comquanto seja das de maior receptividade de calor, parece, entretanto, impor-se por diversas razões, e sem prejuízos apreciáveis".(Ibidem,Ibidem.) Pode-se pensar numa escolha arbitraria da cor ou conveniente por razões econômicas. Mas entre outros motivos, como os objetivos educacionais eram também patrióticos, o azul marinho e o branco dialogavam com as cores da bandeira do estado do Pará. O uniforme parecia também expressar noções de asseio, recato e moral que deveriam ser o cartão de visitas das alunas.

O governador, Eneas Martins, em 1916 acatou integralmente a sugestão do diretor e tornou-a obrigatória, seguindo as mesmas especificações do ofício que recebeu de Eládio Lima. Pela Portaria de 5 de julho do mesmo ano, era marcado um prazo de quarenta dias para as alunas adequarem-se a determinação legal. (Ibidem, Ibidem) Alunas e seus uniformes ficarão intimamente associados à EN nas diversas representações feitas a partir da cidade.

$\mathrm{O}$ uso do uniforme se tornou tão rigoroso que às vezes atrapalhava outras atividades que deveriam ser consideradas mais importantes como assistir aulas e fazer provas. Ora, como o projeto educativo não se limitava aos conteúdos formais, fazia parte de um currículo maior e às vezes oculto a necessidade de disciplinar comportamentos em torno de atos repetitivos, cumprir horários rigidamente cronometrados e obedecer a regulamentos, então se pode entender a lógica do que seria apenas aparentemente um comportamento neutro, o uso do uniforme tornava-se essencial.

Exm $^{\circ}$ Sr. Director da Escola Normal. Adolphina da Silva Motta, mãe de Anna da Silva Motta, alumna do $4^{\circ}$ anno dessa Escola, vem pedir a V Exc ${ }^{a}$ se digne mandar submetter a dita alumna á composição do mez de Julho, visto como, naquela occasião, impossível lhe foi comparecer á Escola, por não possuir botas de salto baixo, nem tão pouco haver no mercado." (IEEP. CorrespondêncialRequerimento: Recibo de entrada de correspondência: Recibo de Entrega de Correspondência :6 de março de 1911 a 2 de outubro de 1919).

Percebe-se nesse documento que componentes da farda, como calçados, acabavam em algumas ocasiões, sendo obstáculo ao comparecimento às aulas das estudantes, muitas vezes independente de suas vontades. Poderia também ser utilizado como mecanismo de adiar avaliações. A força da tradição do uniforme é tão forte que até os dias de hoje, no IEEP, antiga Escola Normal, mantem-se vestígios desse primeiro, pois o atual compõe-se ainda de saia de algodão azul marinho, agora extremamente curta em algumas alunas, e blusas branca com distintivos indicando a série nos bolsos. Pode-se optar também por calças compridas da mesma cor.

Símbolo cobiçado pelas alunas, não apenas por embelezar suas mãos, mas especialmente por visibilizar seu grau de formação, o anel de colação era outro dispositivo de poder, distinção e prestígio (FREYRE. 2002) que conformava o conjunto dos símbolos representativos da EN. A primeira referência encontrada a respeito desse objeto é um decreto de Lauro Sodré de 16de setembro de 1896: "Os professores normalistas do Estado, alem de seu diploma, poderão usar de um annel distinctivo cuja pedra será a onyx cravada em ouro, tendo burilado no cimo, assim como nos lados, um livro e uma pena". (PARÁ. Actos e decisões do Governo 1896.) Os Regulamentos de 1900 e 1903 repetiam o conteúdo do decreto a respeito do anel. Nas disposições posteriores foi suprimida a menção aoseu uso, o que não significaria necessariamente sua supressão. 
O uso de anel, além de ir ao encontro de um hábito muito arraigado na sociedade brasileira da época, dialogava com símbolos ligados ao letramento, essenciais a uma vertente do discurso iluminista e também partilhado por um cientificismo evolucionista e modernizador em escala internacional.

Quanto ao hino, a escola teve o seu primeiro em 1902, embora não oficial. Escrito pelo professor de francês da escola Marques de Carvalho e musicado pelo maestro e diretor do Instituto Carlos Gomes, Menelau Campos, o hino foi executado pela primeira vez na formatura de uma turma em 27 de novembro de 1904. Cantado por um coral de alunas no início e no final das solenidades. Tem como título: "Despedida às Normalistas Diplomadas". O hino dialoga ainda com certa visão iluminista de vencer as trevas da ignorância com a luz do saber, embora se reporte às dificuldades durante o aprendizado: "ao proveitoso e moirejante estudo" apontava para um novo começo: "Vae começar a vida"! Apelava para a virtude e brandura durante a profissão. Sinalizava significativamente para ao duplo papel que se esperava das mulheres no futuro: "[...] Ide aclarar as ténebras do nada; /Do corpo e d'alma levedae os pães; /Que no lar e na escola abençoada, /Um dia duplamente sereis mãe". (SOUZA, 1972).

As referências aos atributos ligados ao feminino estão claramente explicitadas quando o autor se refere à virtude, brandura, ao pão e consequentemente ao lar, e mais explicitamente a sua dupla maternidade enquanto mãe (que em função da virtude se daria necessariamente através de um casamento, reconhecido pela Igreja e pela Pátria) e professora.

Em 07 de julho de 1920, Elias Tavares Vianna, diretor da EN, solicitava a oficialização de dois novos hinos que foram apresentados por ocasião da colação de grau da turma daquele ano. Explicava que o hino anterior não tinha agradado. Agora Eustáquio de Azevedo e Rocha Moreira prepararam as letras do hino de saudação e outro de despedida. O professor Manoel Paiva teria musicado as letras. E continuava: "Por ocasião da última festa de collação de grau V. Exc. teve a oportunidade de ouvir a canção e o hymno alludidos, e, segundo fez logo sentir, achou-os digno dos seus autores". (Idem).

O Hino de Saudação reportava-se ao difícil trabalho do professor, similar a um calvário, mas também juncado de flores. Na verdade, a prática do magistério não era vista como uma profissão qualquer, mas como missão. E em nome desse estatuto era possível aceitar condições de salários baixos e muitas vezes com atraso. Lembrava ainda da importância da educação para o engrandecimento da Pátria. As referências a símbolos cristãos continuavam muito fortes, mesmo se tratando de um hino relacionado a uma escola que deveria ser laica. (Ibidem, Ibidem).

Resumia ainda as representações acerca do professor. Negava-se a presença esmagadora de formandas ao usar as expressões sempre no masculino: missionários, missionário, bom lavrador, companheiros. Lembrava-se do sacrifício cristão e da Pátria. Estava aí contido o cerne de um currículo ocultamente poderoso: submissão feminina, aceitação das condições quase sempre precárias do exercício do magistério e consequentemente das condições sociais de opressão e desigualdade que eram mascaradas em nome de uma unidade maior: a Pátria.

A Canção da Despedida também dá algumas pistas acerca das representações desejadas pela escola sobre a figura da professora. Enfatizava aspectos femininos e de sacrifício como "Entre flores, cumprindo árdua missão [...]. Vós sóis as mensageiras da esperança /O futuro da pátria a irradiar! Adeus! Sêdes felizes!” (Ibidem, Ibidem) Enquanto o primeiro hinotinha características e expressões mais masculinas como: "[...] Pode o livro, uma raça viril preparar" (Ibidem, Ibidem), aspectos que destoariam da condição feminina, 
o segundo, centrava sua referencia apenas nas formandas. Questiona-se então, quais os sentidos dos consumos dessas canções para mulheres e homens da EN.

Uma hipótese a respeito do porquê da substituição do hino de 1902 pelos de 1920 pode ser formulada. Além do menor número de versos, expressões e palavras menos rebuscados, portanto, mais fáceis de serem gravados, os hinos de 1920 sintetizavam melhor o que os dirigentes da escola pensavam a respeito de seus objetivos e de suas/seus formanda(o)s. Já o primeiro era cheio de palavras carregadas de forte arcaísmo, erudição ou exotismo mesmo para a época como: abrolhos, aljôfar, ibirarema, ténebras, punge, influenciado por um romantismo já passadiço.

\section{Considerações Finais}

É possível perceber e concluir que a Escola Normal no Pará, principalmente nos períodos da modernização pelos quais passou a cidade de Belém do Pará foi cenário do fortalecimento e divulgação dos objetivos republicanos. Nesse sentido, a escola utilizou recursos para chamar a atenção do publico, ganhando notoriedade e então se afirmando como terreno fértil para o desenvolvimento do progresso e retirar as trevas existentes do regime anterior.

Assim, o prédio da Escola Normal era visto como um monumento que representava a modernização. As festas de formatura utilizavam recursos pouco usuais no Brasil, mas comuns na França, causando um esplendor naqueles que assistiam o evento. Os discursos pronunciados durante essas cerimonias engrandeciam e prometiam que a escola viria a superar a estagnação escolar.

O diploma de normalista era visto como símbolo de diferenciação em meio à sociedade. Quanto ao uniforme representava a escola perante a cidade, engradecia as alunas, trazendo-lhes respeito, sem esquecer que principalmente era um mecanismo de controle social. $\mathrm{O}$ anel de formatura, hábito generalizado no país, era associado à ideia de letramento, daquele que ocupa um lugar diferenciado na sociedade. Quanto aos hinos dessa instituição, eram uma forma de representar o difícil oficio de professor, mas também como forma de legitimar o espaço que a Escola Normal passaria ocupar como o local de mudança do ultrapassado para o moderno, higiênico e civilizado.

\section{Fontes administrativas:}

ARQUIVO PUBLICO DO ESTADO (PARÁ). APEP. . Área: educação e cultura: fundo: secretaria do governo. Serie:Oficios: (educação) 1891-1900)

PARÁ. Legislação de 1895. Parte II. Belém: Diário Oficial, 1896

PARÁ. Decretos do Governo Republicano do Estado do Pará. 1891. Belém: Diário Oficial, 1894.

PARÁ. Actos e Decisões do Governo 1896. Belém: Diário Oficial, 1897.

APEP. Secretaria do Governo. Escola Normal: Oficios: 1891-1900.

APEP. Secrataria do Governo. Educação: 1895, 1896, 1897, 1899.

APEP. Secretaria do Governo: Educação: 1895, 1896, 1897, 1898, 1899.

APEP. Secretaria Do Governo. Educação. Oficios. 1895, 1896, 1897, 1898, 1899. 
IEEP. (arquivo não classificado). Correspondêncial Requerimento: Recibo de entrada de correspondência: Recibo de Entrega de Correspondência (6 de março de 1911 a 2 de outubro de 1919).

\section{Impressos}

Em favor dos órfãos: As festas da Escola Normal. A República, Belém, p.1, n.665, 07 de setembro de 1893.

OLIVEIRA, Virgilio. "Discurso pronunciado pelo Diretor da Instrução, dr. Virgilio Cardoso de Oliveira, presidindo a sessão solemne de entrega de diplomas ás normalistas que concluíram o respectivo curso em março do decorrente anno". A escola: revista de ensino. Belém, p.382.4 de julho de 1900.

\section{Referências:}

ANDERSON, Perry. "Modernidade e Revolução". Novos Estudos CEBRAP, São Paulo, n'14,fev 1986,pp.2-15.

BERMAN, Marshall. Tudo que é sólido se desmancha no ar: a aventura da modernidade. São Paulo: Companhia das Letras, 1992.

CASTRO. Fábio Fonseca de. A Cidade Sebastiana: era da borracha, memória e melancolia numa capital da periferia da modernidade. Belém: Edições do Autor,2010.

FREYRE, Gilberto. Ordem e Progresso: introdução à História da Sociedade Patriarcal no Brasil. In: SANTIAGO, Silviano (Coord). Interpretes do Brasil. Rio de Janeiro: Nova Aguilar S/A. 2002.

GARCÍA CANCLINI, Néstor. Culturas Híbridas: estratégias para entrar e sair da modernidade. $4^{a}$ ed. São Paulo: Editora da Universidade de São Paulo,2008.(Estudos Latinoamericanos, 1).

SOUZA, Rosa de Fatima de. Templos de Civilização: a implantação da escola primaria graduada no estado de São Paulo (1890-1910). São Paulo: UNESP, 1998.

SOUZA, Altamir. Apontamentos para a História do Instituto de Educação do Pará. Belém, 1972.

\section{Notas}

${ }^{1}$ Professor da Universidade da Amazônia

${ }^{2}$ Curso de Licenciatura em História da Universidade da Amazônia.

${ }^{3}$ Entende-se a modernização enquanto conjunto de processos sociais gestado por descobertas científicas, revoluções industriais, transformações demográficas, urbanização acelerada, os movimentos de massa impulsionados pelo mercado mundial. Algo sempre em movimento, a partir do século XV e XVI, cuja intensidade manifesta-se em tempos presentes. Processo esse altamente polimorfo e excludente capaz de conviver com temporalidades culturais distintas e sofrer, portanto resistências, enfrentamentos e negociações por parte de uma ampla gama de sujeitos sociais. A modernidade seria a experiências históricas dessas modificações.

${ }^{4}$ A partir daí, EN será abreviatura para Escola Normal.

Recebido: abr/15 Aprovado: jun/15 